\title{
IDENTIFICACIÓN Y CLASIFICACIÓN DE LOS MICROHÁBITATS DE AGUA DULCE
}

\author{
Mauricio GARCÍA, ${ }^{1}$ Antonio VERA, ${ }^{1}$ CeSAR Joho BENETTI² ${ }^{2}$ Ligia BLANCO ${ }^{3}$ \\ ${ }^{1}$ Centro de Investigaciones Biológica (CIB), Facultad de Humanidades y Educación, Edif. de Postgrado, La \\ Universidad del Zulia, Venezuela. \\ ${ }^{2}$ Departamento de Ecología y Biología Animal, Facultad de Biología, Universidad de Vigo, Campus Lagoas \\ Marcosende, 36310, Vigo, España. \\ ${ }^{3}$ Fundación La Salle de Ciencias Naturales, Ciudad Guayana, Edo., Bolívar, Venezuela. \\ e-mail: <meruidae2014@gmail.com>,<ajvera68@gmail.com>,<cjbenetti@gmail.com>, \\ <lblancobel@gmail.com>
}

Recibido: 20/02/2015; aceptado: 11/02/2016

\begin{abstract}
García, M., Vera, A., Benetti, C. J. \& Blanco, L. 2016. Identificación y clasificación de los microhábitats de agua dulce. Acta Zoológica Mexicana (n. s.), 32(1): 12-31.
\end{abstract}

RESUMEN. Se identifican una serie de microhábitats relacionados con las aguas dulces, y su respectiva clasificación habitalógica, mediante la propuesta de una disciplina científica denominada habitalogía. Se agrupan en un conjunto de sistemas: sistema de manto residual de hojarasca, sistema de escorrentía, sistema fitotelmata, sistema termal, sistema troglobio, sistema morichal y sistema antropógeno y se mantienen los ya establecidos como los sistemas limnicos (léntico y lótico). Se estudia una serie de diferentes espacios húmedos presentes en los ecosistemas acuáticos de Venezuela, basados en la recolección de insectos acuáticos y semiacuáticos, en su mayoría coleópteros. Se analizan tres humedales naturales de agua dulce en Venezuela como el ribereño, palustre y lacustre, además de los espacios húmedos generados por la acción antrópica. Entre los espacios húmedos se diferenciaron: Anpógeno, Atrix, Axis, Caenum, Caulae, Ediscon, Folia Decidunt, Glarea, Hercircum, Higropétrico, Humu, Madidu, Petra, Rabpet, Radix, Ramentum, Raupet, Spaqua, Spathis, Supaqua, Termali, Trogli, Xilonaq. Se caracterizan individualmente y se demuestra una asociación, superposición y la localización evidente de cada sistema. Se presenta un cuadro clasificatorio, desde el punto de vista de la habitalogía y un esquema habitalógico de los microhábitat, así como fotografías de los microhábitats.

Palabras clave: habitalogía, humedal, insectos acuáticos, sistemas de microhábitat, Venezuela.

\section{INTRODUCCIÓN}

La habitalogía, en términos generales, se define en esta investigación como la identificación, diversificación, diseminación y clasificación de los espacios húmedos y terrestres y cómo se distribuyen en un conjunto de sistemas de agua dulce y sistemas terrestres, y su respectiva colonización, por parte de las especies.

El principal objetivo de este estudio es establecer la habitalogía, como una nueva disciplina que permita es-
García, M., Vera, A., Benetti, C. J. \& Blanco, L. 2016. Identification and classification of freshwater microhabitats. Acta Zoológica Mexicana (n. s.), 32(1): 12-31.

ABSTRACT. A series of microhabitats related to freshwater, and their respective classification habitalogical identified by proposing a scientific discipline called Habitalogy. They are grouped into a set of systems: system residual leaf litter, runoff system, phytotelmata system, thermal system, troglobitic system morichal system and anthropogenic system and kept those already established as the limnic systems (lentic and lotic). A number of different wet rooms in aquatic ecosystems of Venezuela is studied, based on the collection and semi aquatic insects, mostly beetles is studied. Three natural freshwater wetlands are discussed in Venezuela as the coastal, marsh and lake, plus wet spaces generated by human action. Among the wet rooms they were differentiated: Anpógeno, Atrix, Axis, Caenum, Caulae, Ediscon, Folia Decidunt, Glarea, Hercircum, Hygropetric, Humu, Madidu, Petra, Rabpet, Radix, Ramentum, Raupet, Spaqua, Spathis, Supaqua, Termali, Trogli, and Xilonaq. And they characterized individually association evident overlap and location of each system is shown. A classification table is presented from the point of view of Habitalogy and scheme habitalogical the microhabitats as well as photographs of microhabitats.

Keywords: Habitalogy, wetland, aquatic insects, microhabitat systems, Venezuela.

tudiar específicamente la clasificación de los espacios húmedos, lo cual es posible mediante un proceso clasificatorio de los entornos ambientales, donde las especies se desarrollan, se alimentan y se reproducen.

Un hábitat no es un lugar donde vive una especie, es un lugar donde viven varias especies de diferentes taxones y diferentes ciclos biológicos. Es a partir de procesos naturales que se producen las transformaciones taxonómicas, las cuales permiten a las especies evolucionar en sus entornos y producir descendencias, capaz de soportar 
y de adaptarse a las rigurosidades y condiciones nuevas de un ambiente en evolución.

La habitalogía permite identificar el lugar específico al cual pertenecen o donde realmente habitan las especies de insectos, en los espacios de agua dulce. Trata de clasificar esos entornos, según sus características naturales y, realiza un seguimiento de su diseminación ambiental, mediante la proposición de diferentes sistemas hidrobiológicos.

Dentro de los espacios naturales que ocupan los insectos se encuentran los ambientes acuáticos, los cuales se consideran entre los de mayor diversidad biológica. Estos espacios, incluyendo los medios artificiales (infraestructuras producidas por la actividad antrópica), les ofrecen a los insectos una alta diversidad de microhábitat, en los que han tenido un inmensurable éxito para la explotación de los recursos existentes.

La información sobre los espacios que constituyen hábitats húmedos para los insectos acuáticos, no detallan la especificidad de los mismos. Las investigaciones sobre el tema no resaltan una descripción específica sobre la heterogeneidad de ambientes que se presentan en la naturaleza (Hutchinson 1967; Frissell et al. 1986). Las investigaciones sólo hacen referencia, de manera muy general, sobre la existencia de los ecosistemas lénticos y lóticos.

La literatura actual no reporta la especificidad y heterogeneidad de los diferentes microhábitat que se generan por una diversidad de especies y la distribución de los mismos sobre los ecosistemas húmedos. Frissell et al. (1986), establecen una clasificación de los hábitat desde un marco teórico de un río, hasta llegar a los subsistemas de microhábitat. Welcomme (1980) establece un marco habitalógico a partir del rabión y el ritrón y la segregación de espacios húmedos luego de la riada.

Este estudio aporta información de base que amplía el conocimiento sobre la diversidad de los ecosistemas de agua dulce en el neotrópico y facilita el trabajo a los investigadores sobre la taxonomía y la biogeografía (distribución) de insectos acuáticos. Permite identificar a un determinado organismo ocupando un hábitat específico, delimitando y precisando el espacio particular donde habita la especie como tal.

\section{MATERIAL Y MÉTODOS}

Áreas de estudio. La identificación de los microhábitats húmedos se llevó a cabo a través trabajos de campo y muestreos realizados desde 1998 hasta 2012, durante la recolección de material entomológico y desarrollos de proyectos de investigación relacionados con la faunística y taxonomía de insectos acuáticos.

Se recorrieron diferentes áreas geográficas de Venezuela (occidente incluyendo los Andes, los llanos, parte de la región amazónica y Guayana, parte de la región oriental incluyendo el delta Amacuro), con el objeto de recolectar especies de insectos acuáticos y semiacuático. Se visitaron 18 de los 23 estados del territorio venezolano (se excluyen los estado, Carabobo, Miranda, Nueva Esparta, Vargas y Yaracuy).

Entre los ambientes (Microhábitats) estudiados se incluyen: vasculares acuáticas (macrófitas), interior de raíces en suelo húmedo y/o en el interior de briofitas terrestres y vasculares de agua dulce. Asociadas a niveles de inundación, rocas húmedas y secas, suelos lodoso y arenoso húmedos, depósitos de materiales orgánicos como los suelos húmicos, grava o gravilla, aguas termales y varias formas de fitotelmata, manto residual de hojarasca, morichal, cavernas y escorrentías.

También se estudiaron cuerpos de agua permanentes: como lagos, lagunas, y estanques naturales. Cuerpos de agua no establecidos: como pozas y charcos originados en el corredor ribereño producto de desbordamiento de ríos, represas o por inundaciones provocada por efecto de lluvias. Cuerpos de agua como: estanques o pozos formados en meándros de ríos y remansos producto de sequias, que disminuyen la corriente en los cauces, creándose zonas de menor transporte y acumulamiento de sedimentos.

Se realizaron muestreos establecidos en río y laguna hasta llegar al bosque inundado con diferentes microhábitat: hojas de árboles del bosque inundado, bolas de algas, detrito flotante, maderos flotantes, vegetación acuática, sedimento de la laguna, sedimento de la orilla, hojarasca, etc. y lagunas alargadas producto de cambios de rumbo del río y de lagunas en forma de herradura (oxbow lakes).

La clasificación habitalógica de los espacios húmedos se realizó, determinando un orden mayor como el supra sistemas, que incluye en contexto las aguas dulce continentales, las cuales a su vez contiene los humedales de agua dulce que se encuentran en cualquier parte del mundo como el ribereño, lacustre y palustre.

Estos humedales comprenden todos los cuerpos de agua dulce, sobre los cuales se desarrollan los diferentes sistemas que se encuentran en el corredor ribereño. En los corredores ribereños se forman los microhábitats que los insectos acuáticos y otros organismos utilizan en el desarrollo de sus ciclos vitales.

En cada uno de los microhábitats identificados, nom- 
brado y clasificado, se registran los taxones de las especies entomológicas que fueron recolectadas en el campo entre los años 1998 y 2012. Es necesario resaltar aquí que serán presentadosenvariostrabajosposteriores, debidoasuextenso, en este artículo solo se registran el orden y la familia.

Finalmente los microhábitats asociados a sus respectivos sistemas fueron conformados en 9 grupos (desde la $\mathrm{A}$ hasta la I) y se dispone en cuadros o cuadrículas.

Nomenclatura de términos utilizados en esta investigación para nombrar a los microhábitats identificados. La terminología utilizada en esta investigación, para designar a los microhábitats identificado durante el reconocimiento de los mismos, se basa en vocablos latinos. En algunos casos vocablos griegos, en otros casos, vocablos de lenguas indígenas. Algunos nombres, son la suma de las primeras silabas de dos vocablos latinos y en otra son derivaciones a partir de los mismos vocablos y la intención de los autores.

\section{RESULTADOS}

Existen hábitats húmedos que muestran tendencia a ser específicos para algunos grupos taxonómicos en particu- lar, mientras que otros microambientes son más generalistas.

Sumando a todo esto se ilustra que los espacios húmedos pueden interrelacionarse en forma asociativa, en toda la extensión y la extensión de los humedales.

Clasificación habitalógica. Se parte de la condición de un supra sistema para considerar los grandes espacios húmedos que contienen la diversificación de ambientes y sus entornos.

Supra Sistema $\rightarrow$ Aguas dulces continentales (los diferentes humedales de agua dulce que conforman las aguas continentales).

Super Sistemas $\rightarrow$ El humedal (río, rápidos, remansos, manantiales, quebradas, lagos y lagunas, charcas y pozos, pantanos, ciénagas, vegetación retenedora de agua, cavernas húmedas, manantiales azufrosos, cascadas, saltos y escorrentías, mantos de hojarascas y morichales).

Sistemas $\rightarrow$ Antropógeno, escorrentía, fitotelmata, manto residual, morichal, límnicos (léntico y lótico), termal y troglobio.

Microhábitats $\rightarrow$ Anpógeno, Atrix, Axis, Caulae, Caenum, Ediscon, Folia Decidunt, Glarea, Hercircum, Higropétrico, Humu, Madidu, Moriche, Petra, Rabpet, Radix, Ramentum, Raupet, Spaqua, Spathis, Supaqua, Termali, Trogli y Xylonaq.

\section{Grupo A}

\section{Microhábitats húmedos asociados al sistema Límnico subsistema léntico}

El sistema límnico/léntico se caracteriza por presentar muy poca velocidad de arrastre de agua a nula: los lagos, lagunas, pantanos, ciénagas, charcos y pozos forman parte de este sistema. Se han identificado nueve microhábitats:

\begin{tabular}{|l|l|}
\hline CAENUM & Vocablo latino que significa cieno, sedimento orgánico en los fondos de pequeños cuerpos de agua. \\
\hline $\begin{array}{l}\text { Microhábitat Caenum } \\
\text { (Fig. 33, 35) }\end{array}$ & $\begin{array}{l}\text { Existe en los sustratos blandos, en los fondos de algunos cuerpos de agua que ocupan una zona litoral poco } \\
\text { profunda y pequeños cuerpos de agua en el corredor ribereño. }\end{array}$ \\
\hline Taxones residentes & $\begin{array}{l}\text { Órdenes y familias de insectos acuáticos encontrados aquí: Coleoptera (larvas y adultos sujetos al material } \\
\text { sólido de la familia Dytiscidae e Hydrophilidae), Diptera (larvas de Chironomidae, Simulidae, Syrphidae y } \\
\text { Tabanidae), Ephemeroptera (larvas de Polymitarcyidae), Lepidoptera (larvas de algunas especies de la familia } \\
\text { Piralidae), Neuroptera (larvas de Osmilidae y Sisiridae), Odonata, Plecoptera (larvas) y Trichoptera (larvas), } \\
\text { Hydropsychidae }\end{array}$ \\
\hline GLAREA & $\begin{array}{l}\text { Vocablo latino que significa grava o gravilla, sustrato de microrrocas en los márgenes de algunos cuerpos de } \\
\text { agua. }\end{array}$ \\
\hline Microhábitat Glarea & $\begin{array}{l}\text { El microhábitat húmedo glarea existe, entre los espacios o poros formados, entre la mezcla de los fragmento } \\
\text { de rocas y piedras, que son más grueso que la arena. Partículas pequeñas entre 0.5 a } 2 \text { cm de diámetro, que se } \\
\text { encuentran bajo o a nivel de la superficie de algunos cuerpos de agua. }\end{array}$ \\
\hline Taxones residentes & $\begin{array}{l}\text { Órdenes y familias más comunes de especies de insectos acuáticos encontrados: Coleoptera (adultos de } \\
\text { Dytiscidae, Hydrophilidae, Lepiceridae), Hemíptera (Naucoridae). }\end{array}$ \\
\hline HERCIRCUM & $\begin{array}{l}\text { Término derivado formado por dos vocablos latinos; herba que significa hierba y circum que significa } \\
\text { alrededor. Cuerpo de agua inundado de hierbas. }\end{array}$ \\
\hline $\begin{array}{l}\text { Microhábitat Hercircum } \\
\text { (Figs. 11, 22, 25, 31, 34, 35) }\end{array}$ & $\begin{array}{l}\text { Este microhábitat húmedo existe, en el espacio circundante entre las plantas herbáceas (macrófitas) de una zona } \\
\text { inundada y sobre la misma hierba, de algunos cuerpos de agua. }\end{array}$ \\
\hline
\end{tabular}




\begin{tabular}{|c|c|}
\hline Taxones residentes & $\begin{array}{l}\text { Órdenes y familias de especies de insectos acuáticos encontrados: Coleoptera (larvas y adulto de; } \\
\text { Curculionidae, Dytiscidae, Haliplidae, Hydrochidae, Hydrophilidae, Limnichidae, Luthrochidae y Noteridae), } \\
\text { Ephemeroptera (larvas), Hemiptera (larvas y adultos de; Belostomatidae, Corixidae, Hebridae, Hydrometridae, } \\
\text { Gerridae, Macroveliidae, Mesoveliidae, Naucoridae, Nepidae, Notonectidae, Veliidae), Megaloptera (larvas de } \\
\text { Corydalidae), Plecoptera (larvas), Trichoptera (larvas) Odonata (larvas). }\end{array}$ \\
\hline HUMU & Del vocablo latino humus que significa tierra blanda. \\
\hline Microhábitat Humu & $\begin{array}{l}\text { Este microhábitat húmedo se presenta en el sustrato lodoso, irrigado de material vegetal en descomposición } \\
\text { y cargado de un exceso de humedad y materia orgánica en disolución. }\end{array}$ \\
\hline Taxones residentes & $\begin{array}{l}\text { Orden y familias de especies de insectos acuático o semiacuático: Coleoptera (adultos y larvas; Georissidae, } \\
\text { Hydraenidae, Hydrophilidae, Hydrochidae). }\end{array}$ \\
\hline MADIDU & Vocablo latino que significa húmedo. \\
\hline $\begin{array}{l}\text { Microhábitat Madidu } \\
\text { (Figs. 18, 19, 21) }\end{array}$ & $\begin{array}{l}\text { El microhábitat madidu se presenta sobre los objetos orgánicos o inertes, que se mantienen húmedo por una } \\
\text { delgada película de agua que lo envuelve. Estos objetos se encuentran en superficies húmedas de algunos } \\
\text { cuerpos de agua de escasa profundidad. }\end{array}$ \\
\hline RADIX & Vocablo latino que significa raíz. Raíces inundadas sobre el suelo acuoso. \\
\hline $\begin{array}{l}\text { Microhábitat Radix } \\
\text { (Figs. 5, 7, 18) }\end{array}$ & $\begin{array}{l}\text { Se forma en la maraña de raíces de plantas vasculares, sobre el sustrato húmedo y areno-lodoso, } \\
\text { que las contiene en la superficie de pequeños cuerpos de agua. En algunos casos se encuentran asociada } \\
\text { a las riberas de suaves corrientes. }\end{array}$ \\
\hline Taxones residentes & $\begin{array}{l}\text { Órdenes y familias de especies de insectos acuáticos colectadas en este tipo de ambientes: Coleoptera } \\
\text { (Dytiscidae, Hydrochidae, Hydrophilidae, Lepiceridae), Diptera (Ceratopogonidae), Ephemeroptera } \\
\text { (Caenidae,), Hemiptera (Naucoridae), Trichoptera (Hydroptilidae, Polycentropodidae, Hydropsychidae), } \\
\text { Odonata, Lepidoptera. }\end{array}$ \\
\hline RAMENTUM & Vocablo latino que significa arena. Bancos de arena sobre las riberas de los cuerpos de agua. \\
\hline $\begin{array}{l}\text { Microhábitat Ramentum } \\
\text { (Figs. 1, 6, 20, 31) }\end{array}$ & $\begin{array}{l}\text { El ramentum se encuentra entre los espacios intersticiales, formado por las partículas de arena entre } 2 \text { a } 3 \mathrm{~mm} \\
\text { de diámetro, en pequeños bancos, que se encuentran sumergidos, o a nivel de la superficie del agua en riberas } \\
\text { y orillas de grandes y pequeños cuerpos de agua. }\end{array}$ \\
\hline $\begin{array}{l}\text { Microhábitat Spaqua } \\
\text { (Figs. 12, 24, 31) }\end{array}$ & $\begin{array}{l}\text { El microhábitat se presenta entre las aguas someras, de profundidad variable, de pequeños cuerpos de agua. Las } \\
\text { especies de insectos nadadores se desplazan libremente en el medio o flotan sobre la superficie, además } \\
\text { de poder fijarse en el sustrato de fondo, mientras se encuentran inactivos. Emergen solo para el intercambio } \\
\text { de gases o para emigrar hacia otros hábitats. }\end{array}$ \\
\hline Taxones residentes & $\begin{array}{l}\text { Se han registrados órdenes y familias de especies de insectos y arácnidos acuáticos en este tipo de ambiente: } \\
\text { Acárida, Coleoptera (Dytiscidae, Haliplidae, Hydrochidae, Hydrophilidae, Hydroscaphidae, Noteridae); } \\
\text { Diptera (Culicidae, Tipulidae); Hemiptera (Belostomatidae, Corixidae, Naucoridae, Notonectidae); } \\
\text { Ephemeroptera (larvas); Plecoptera (larvas), Odonata. }\end{array}$ \\
\hline SUPAQUA & $\begin{array}{l}\text { Término derivado formado por dos vocablos latinos; superficie = superficie y aqua = agua. Espacio creado } \\
\text { sobre la superficie del agua. Moverse sobre la superficie del agua. }\end{array}$ \\
\hline $\begin{array}{l}\text { Microhábitat Supaqua } \\
\text { (Figs. 12, 24, 25, 32) }\end{array}$ & $\begin{array}{l}\text { Este espacio húmedo se presenta y se desarrolla sobre la superficie del agua, de pequeños cuerpos de agua, } \\
\text { con poca extensión superficial. Las especies se desplazan o permanecen sobre ella, sin romper la tensión } \\
\text { superficial. Algunos de estos organismos, presentan en sus patas y abdomen una pubescencia hidrófoba, } \\
\text { que repelen las moléculas de agua y permite deslizarse sobre ella y recorrer largas distancias sin hundirse. }\end{array}$ \\
\hline Taxones residentes & $\begin{array}{l}\text { En este medio encontramos generalmente especies semiacuáticas del orden: Hemiptera (Gerridae, Hebridae, } \\
\text { Hydrometridae, Macroveliidae, Mesoveliidae, Veliidae); y especies acuáticas del orden Coleoptera (Gyrinidae). }\end{array}$ \\
\hline PETRA & Vocablo latino que significa piedra, roca. \\
\hline
\end{tabular}




\begin{tabular}{|l|l|}
\hline $\begin{array}{l}\text { Microhábitat Petra } \\
\text { (Figs. 5, 14, 17) }\end{array}$ & $\begin{array}{l}\text { Sobre formaciones de roca arenisca con depresiones cóncavas de diámetros y profundidades variables; roca } \\
\text { sedimentaria en los cauces de rápidos y quebradas, con pequeñas depresiones o concavidades. Sobres estas } \\
\text { concavidades y depresiones, el agua se acumula, creando así un ambiente propicio para la colonización. }\end{array}$ \\
\hline Taxones residentes & $\begin{array}{l}\text { Órdenes y familias de especies de insectos acuáticos encontrados en las depresiones de la roca arenisca } \\
\text { y sedimentaria: Coleoptera (Dytiscidae e Hydrophilidae); Hemiptera (Naucoridae) y Odonata. }\end{array}$ \\
\hline
\end{tabular}

\section{Grupo B}

\section{Microhábitats húmedos asociados al sistema Límnico subsistema lótico}

El sistema límnico/lótico se caracteriza por presentar la velocidad de arrastre del agua, por encima de los $10 \mathrm{~m} / \mathrm{s}$ y, en algunos casos, ésta permite la acumulación de sustratos debajo de la superficie del agua: ríos, rápidos, remansos, manantiales y quebradas forman parte de este sistema. Se han identificados seis microhábitats:

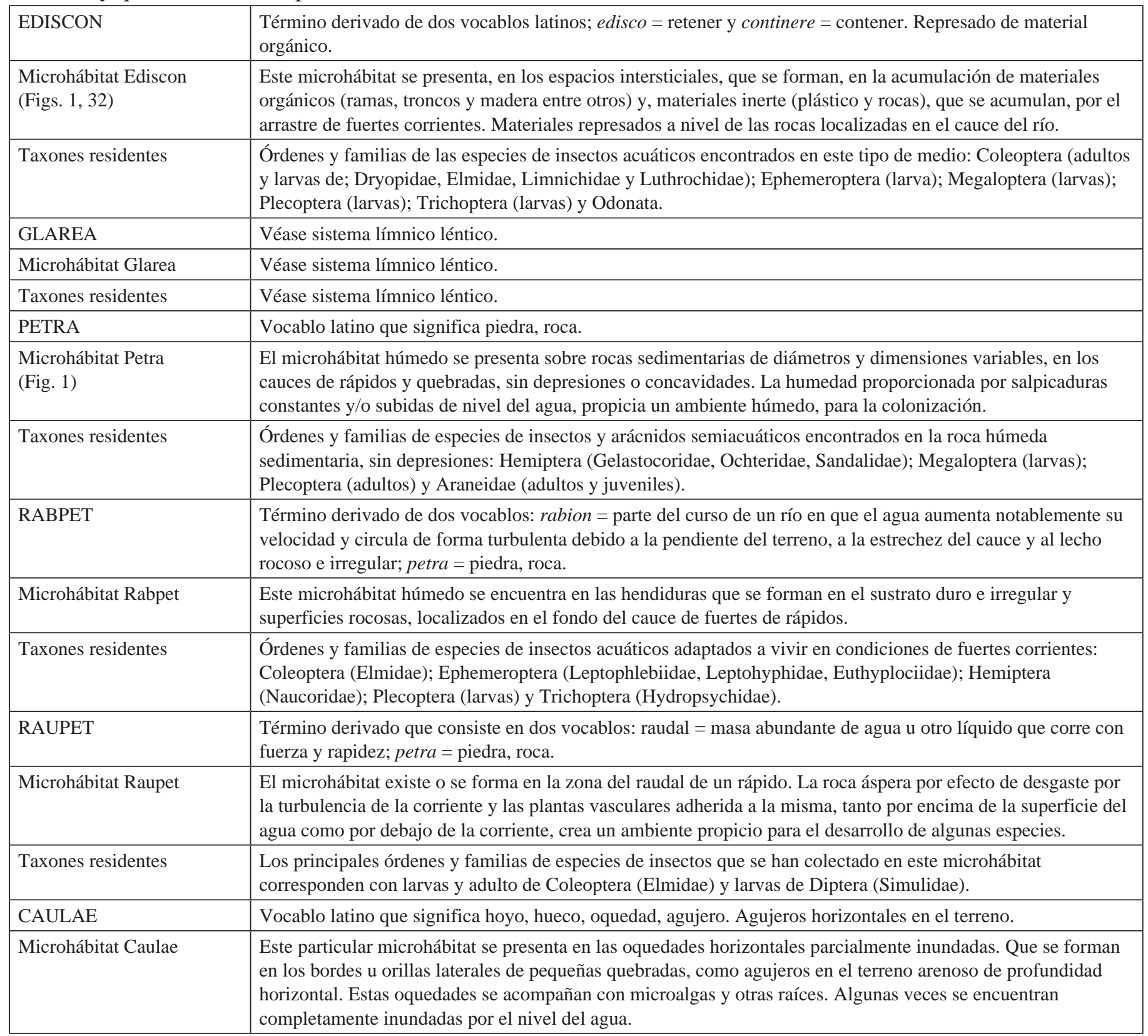


Taxones residentes

Principales órdenes y familias de especies de insectos acuáticos: Coleoptera (Dytiscidae, Hydrophilidae, Hydroscaphidae); Hemiptera (Pleidae) y una familia de Collembola (Sminthuridae).

\section{Grupo C}

\section{Microhábitats húmedos asociados al sistema de Manto Residual del corredor ribereño}

\begin{tabular}{|l|l|}
\hline FOLIA DECIDUNT & Vocablo latino que significa hojarasca, hojas caídas, hojas que caen. \\
\hline $\begin{array}{l}\text { Microhábitat del Folia } \\
\text { Decidunt }\end{array}$ & $\begin{array}{l}\text { El microhábitat de manto residual del corredor ribereño se encuentra entre los intersticios que se forman en el } \\
\text { material vegetal senescente acumulado. Se encuentra localizado tanto en espacios abiertos en la zona boscosa, } \\
\text { como dentro de los cuerpos de agua. }\end{array}$ \\
\hline Taxones residentes & $\begin{array}{l}\text { Órdenes y familias de especies de insectos acuáticos y semiacuáticos presentes en este ambiente: Blattodea; } \\
\text { Coleoptera (Carabidae, Chrysomelidae del genero Donacia, Dryopidae, Dytiscidae, Elmidae, Hydrochidae, } \\
\text { Hydrophilidae, Limnichidae, Lepiceridae, Psephenidae); Diptera (larvas de Syrphidae); Ephemeroptera } \\
\text { (Polymitarcyidae); Hemiptera; Mecoptera (larvas) y Trichoptera (Hydropsychidae, Odontoceridae). }\end{array}$ \\
\hline
\end{tabular}

\section{Grupo D}

Microhábitats húmedos asociados al sistema de escorrentía en el corredor ribereño

Estos ambientes están caracterizados por la forma como el agua se desplaza sobre la superficie rocosa, de forma vertical u horizontal, como desagües naturales o fuertes corrientes.

\begin{tabular}{|l|l|}
\hline HIGROPÉTRICO & $\begin{array}{l}\text { Término derivado de dos vocablos latinos: higro = humedad y pétrico = piedra, roca. La roca húmeda, la piedra } \\
\text { mojada. }\end{array}$ \\
\hline $\begin{array}{l}\text { Microhábitat Higropétrico } \\
\text { de escorrentía vertical; } \\
\text { aguas lentas } \\
\text { (Figs. 13, 21, 27, 29, 30) }\end{array}$ & $\begin{array}{l}\text { El microhábitat de aguas verticales y escorrentía lenta, de caída libre se origina de forma muy particular de } \\
\text { algunos cuerpos de agua como cascadas y saltos. Esta permite el escurrimiento de trazas de agua sobre la roca } \\
\text { vertical. Pero igualmente también se origina una delgada película de agua que se filtra a la superficie, cuando es } \\
\text { época de lluvia y se escurre por la roca. En ambos caso el agua se desplaza de forma lenta en sentido vertical. } \\
\text { En algunos casos el microhábitat se acompaña del crecimiento de briófitas (musgos y hepáticas). }\end{array}$ \\
\hline $\begin{array}{l}\text { Microhábitat Higropétrico } \\
\text { de escorrentía horizontal, } \\
\text { aguas rápidas } \\
\text { (Figs. 2, 4, 9, 15, 18) }\end{array}$ & $\begin{array}{l}\text { El microhábitat de aguas horizontales de escorrentía rápida, se localiza en los intersticios o fisuras que se } \\
\text { forman en la roca, bañada constantemente por la corriente proveniente de rápidos sobre la superficie rocosa. }\end{array}$ \\
\hline $\begin{array}{l}\text { Taxones residentes } \\
\text { Taxidenes y familias de especies encontradas en este tipo de microhábitat húmedo: Coleoptera (Dytiscidae, }\end{array}$ \\
$\begin{array}{l}\text { Elmidae, Hydrophilidae, Hydroscaphidae, Meruidae, Noteridae, Torridincolidae); Hemiptera (Naucoridae, } \\
\text { Ochteridae, Pleidae, Potamocoridae, Sandalidae) y Ephemeroptera (larvas). }\end{array}$ \\
\hline
\end{tabular}

\section{Grupo E}

\section{Microhábitats asociados al sistema Termal en el corredor ribereño}

En el corredor ribereño se encuentra algunas fuentes hidrológicas o particulares cuerpos de agua, donde la temperatura del medio es el factor determinante para propiciar la colonización por parte de los insectos acuáticos. Los manantiales de agua azufrosas son microhábitats muy particulares.

\begin{tabular}{|l|l|}
\hline TERMALI & Término derivado del vocablo latino termo = caliente. Vive en el agua caliente. \\
\hline Microhábitat Termali & $\begin{array}{l}\text { Este espacio húmedo se encuentra asociado a aguas termales. Es un ambiente acuático donde la temperatura del } \\
\text { medio húmedo se encuentra por encima de los } 40^{\circ} \mathrm{C} . \text { Son manantiales de aguas azufrosas. }\end{array}$ \\
\hline Taxones residentes & Un solo orden y una familia: Coleoptera (Hydrophilidae). \\
\hline
\end{tabular}

\section{Grupo F}

\section{Microhábitat asociado al sistema Troglobi}

Existen cuerpos de aguas subterráneas muy particulares de algunos tipos de cavernas. En este medio la luz no es el factor determinante para la colonización por parte de los organismos biológicos. Sin embargo, el medio represen- 
ta un factor determinante que permite y favorece el desarrollo de especies muy particulares con respecto al medio exterior.

\begin{tabular}{|l|l|}
\hline TROGLI & Término derivado del vocablo latino troglobios = caverna, cavernícola. Vive en caverna. \\
\hline Microhábitat Trogli & $\begin{array}{l}\text { El medio húmedo se forma dentro de las cavernas donde se presentan escorrentías o filtraciones de agua o } \\
\text { manantiales subterráneos. }\end{array}$ \\
\hline Taxones residentes & $\begin{array}{l}\text { Son muchos los organismos biológicos adaptados a este medio húmedo. Para esta investigación solo son de } \\
\text { interés las especies de las familias de Coleoptera (Dytiscidae, Hydrophilidae). }\end{array}$ \\
\hline
\end{tabular}

\section{Grupo G}

\section{Microhábitats asociados al sistema Fitotelmata o plantas retenedoras de agua del corredor ribereño}

Este ambiente húmedo está caracterizado por aquellos lugares que forman parte de una planta, sobre los cuales se desarrollan superficies húmedas y/o tienen la capacidad de acumular pequeños volúmenes de agua, que permite crear condiciones propicias para la colonización, por parte de un grupo de organismos biológicos.

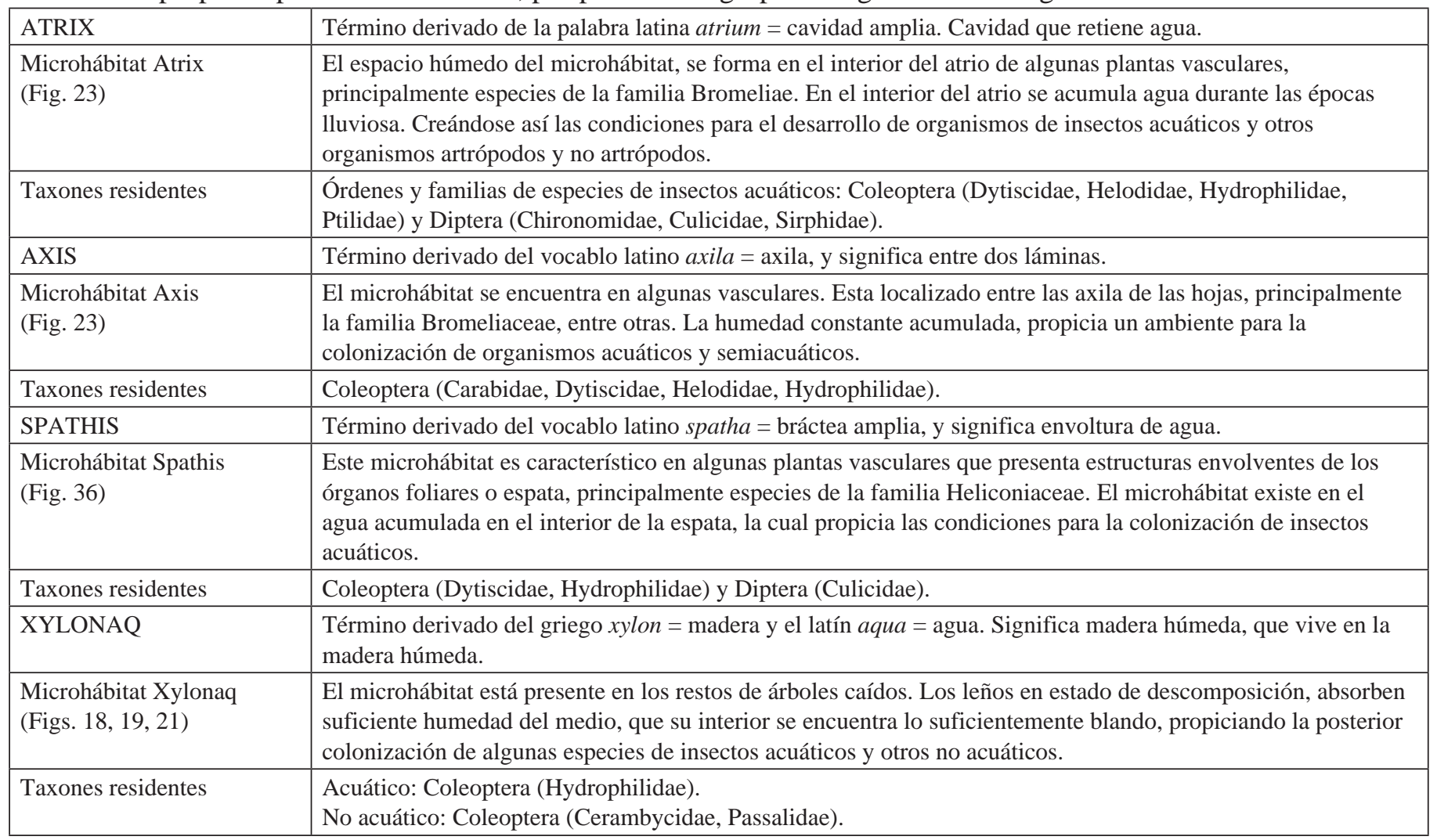

\section{Grupo H}

\section{Microhábitat asociado al sistema Morichal del corredor ribereño}

Los morichales, a diferencia de los Palmares, tienen agua durante todo el año, lo cual los hace un lugar muy abundante en animales y plantas. El agua de los morichales generalmente tiene origen freático, por lo que se mantiene el nivel del agua, aunque no llueva. El color del agua es turbio, causado por la suspensión en el agua de sustancias húmicas.

\begin{tabular}{|l|l|}
\hline MORICHE & Vocablo de origen indígena de la lengua Tupi = árbol. Los morichales son aglomeraciones de la palma moriche. \\
\hline Microhábitat Moriche & $\begin{array}{l}\text { Es el microhábitat más completo de todos los sistemas. Se presenta en toda la extensión del morichal. Es muy } \\
\text { específico en cuanto especies se refiere y a la vez es el más proporcionado en cuanto a medios se refiere. } \\
\text { Está constituido por cada uno de los demás microhábitat anteriores. Está contenido en el conglomerado del } \\
\text { morichal. }\end{array}$ \\
\hline
\end{tabular}




\section{Grupo I}

\section{Microhábitats rurales y urbano asociados al sistema Antropogénico}

Este sistema es de orden cultural, el factor humano es el responsable de su existencia. Esta caracterizado por los asentamientos antropogénico. Las especies asociadas a estos ambientes culturales, se mantienen en un constante proceso adaptativo, a los diferentes cambios ecológicos, producidos por la actividad humana.

\begin{tabular}{|l|l|}
\hline ANPÓGENO & Término derivado del vocablo antropógeno = acción del hombre. \\
\hline $\begin{array}{l}\text { Microhábitat Anpógeno } \\
\text { (Figs. 26, 27, 28, 29, 30) }\end{array}$ & $\begin{array}{l}\text { Los microhábitats húmedos Anpógenos, se localizan donde hay una alta actividad humana como los centros } \\
\text { poblados (urbanos, semiurbanos y rurales). Lagunas de estabilización para la recuperación de las aguas } \\
\text { servidas, charcas temporales para el cultivo del arroz, proveedores de agua (bebederos) para animales, acequias } \\
\text { y pozos para riego en cultivos, canales para el transporte del agua, fuentes en parques y plazas públicas, etc. }\end{array}$ \\
\hline Taxones residentes & $\begin{array}{l}\text { Coleoptera (Dryopidae, Dytiscidae, Histeridae, Hydraenidae, Hydrochidae, Hydrophilidae, Noteridae); } \\
\text { Hemiptera (Belostomatidae, Corixidae, Nepidae, Notonectidae, Gerridae); Diptera (Chironomidae, Culicidae, } \\
\text { Sirphidae) y Odonata (larvas). }\end{array}$ \\
\hline
\end{tabular}

\section{DISCUSIÓN}

Los hábitats en agua dulce ocupan una porción relativamente pequeña de la superficie de la tierra en comparación con los hábitats marinos y terrestres, sin embargo, su importancia es mayor que su área. Los microhábitats presentados aquí, independientemente de los organismos que los ocupan, siempre han existido, siempre han estado allí, siempre han sido parte de la naturaleza y hasta que un organismo la descubre, entonces evoluciona en un microhábitat, debido a que las condiciones del medio, favorecen el desarrollo de la especie.

A partir de nuevas técnicas implementadas en la recolecta de insectos acuáticos hemos evidenciado que su distribución obedece a un criterio de superposición de nichos. Un nicho tiene que ver con el espacio y la función de un organismo en un área determinada. Ambos términos (espacio y función) traducen en el hábitat compartido por una serie de organismo, sobre el cual se desarrollan varios tipos de especies, depredadora, herbívora, omnívora o incluso descomponedora (saprófaga).

Los hábitats se encuentran en un permanente cambio y reconstrucción de sí mismos. Los ambientes acuáticos se encuentran cambiando periódicamente por efecto del clima, procesos tectónicos, etc., que se producen a lo largo de la vida del planeta. Esto produce superposición de nichos que conducen a la utilización de cualquier espacio que ofrezca refugio y alimentos.

Hay que ser más experimental y más improvisado al momento de realizar un muestreo que nos lleve a realizar colectas extraordinarias de especies de insectos acuáticos. Se deben realizar muestreos en lugares no acostumbrados. En algunas ocasiones hay éxito en la recolecta de especies no registradas. Acertamos a la primera, pero en otras simplemente no encontramos nada, pero las especies están allí, y se encuentran en permanente movimiento.

Los cambios climáticos, las temporadas de lluvias, producen que las especies emigren hacia nuevos espacios, y los espacios anteriores, pueden ser recolonizados por otras en desarrollo.

La habitalogía como ciencia busca estudiar los procesos de transformación de los hábitats. Permite reconocer aquellos espacios que no se consideran como probables. Hay un número de especies que recolectamos en situaciones inesperadas, como en un trampeo luminoso. No sabemos de donde provienen estas especies. No conocemos sus hábitats específicos. Pero están allí, en el ambiente que recorremos, sólo no lo reconocemos.

Muchas especies que han sido registradas en los hábitats clásicos como léntico y lótico, no especifica el hábitat real de las especies. Un hábitat léntico o un hábitat lótico pueden ser extenso, y las especies pueden provenir de cualquier parte. O si la colectamos en la orilla de un río, es posible que su hábitat real sea la hojarasca. Y cuando tratamos de hallarla basado en la descripción de su recolecta, nunca la encontraremos, porque no es su nicho. Existen razones para que las especies se encuentren en lugares fuera de su verdadero entorno. Un desborde de un río, un deslave, una inundación, etc., cualquiera de estas razones, pueden llevar a una especie a ser recolectada 
fuera de su ambiente, y pensaremos que es de allí, donde la encontramos.

Habitalogía de los microhábitat (véanse Figs. 1-36) Como se dijo antes, los microhábitat siempre han existido, a medida que los descubrimos, nos damos cuenta de la inmensa distribución y adaptación de las especies. La recolecta de ejemplares, se debe realizar en función de los hábitats, no sólo de las especies.

La diversificación de hábitat, se refiere a la cantidad de hábitats que existen en un área determinada, pero no los conocíamos.

La diseminación nos dice, la forma como están distribuidos, en el ambiente que conocemos. Se encuentran por todos lados.

Este trabajo identifica una serie de ambientes desconocidos, sobre todo para el investigador joven. Ofrece un espacio promisorio extendido de una serie de lugares que pueden ser muestreados. En un mismo lugar, es posible encontrar, una variedad de microhábitat cercanos, uno del otro, habitado por especies diferentes. Sólo les separa una corriente de agua, un cumulo de hojarasca o un pequeño banco de arena, entre otros.

Los dos primeros grupos de microhábitat están asociado al sistema límnico. Son dos los subsistemas limnicos; sistema límnico léntico y sistema limnico lótico (véase grupo A y B).

El microhábitat caenum, contienen sedimentos inertes (arcillas y limo) y partículas orgánicas (detritus). Esta materia sedimentada, propicia el desarrollo de nichos, para un gran número de especies filtradoras. También sirve de refugio, contra depredadores que nadan libremente en el cuerpo de agua.

Al remover el sustrato acumulado en el fondo, puede observarse a las especies caenumícolas, en su mayoría larvas. Estas pueden respirar utilizando diferentes estructuras como traqueobranquias o plástrones. Los adultos deben nadar hasta la superficie, o desplazarse por el sustrato, hasta llegar a la orilla, para el intercambio de gases.

El microhábitat glarea, es un espacio húmedo localizado cerca de los márgenes de algunos cuerpos de agua, donde la profundidad no exceda los 3 o $5 \mathrm{~cm}$ y en algunos casos la lámina de agua se encuentra por debajo de superficie granulosa. Las especies glarícolas, se encuentran entre el intersticio formado por los granos. Estos depósitos de microrocas que presentan espacios intersticiales facilitan la circulación del agua y, la acumulación de sedimentos orgánicos o detritus. Igualmente ofrece refugio contras depredadores y aislamiento contra los cambios de temperaturas. Este tipo de ambiente se encuentra en los corredores ribereños. Estos hábitats tienden a desaparecer con la crecida de los ríos. Es un microhábitat compartido por los subsistemas limnicos.

En el microhábitat hercircum, las especies hercircumicolas nadan libremente entre los espacios herbales, flotan o se fijan a hojas, tallos y raíces de plantas macrófitas como Juncaceae (Juncu sp.) y Cyperaceae (Cyperus sp.) entre otras especies vasculares terrestres que se encuentran en áreas inundadas. En la planta flotante Eichhornia crassipes se encuentran larvas acuáticas de curculiónidos alimentándose, haciendo galerías en los pecíolos y los adultos permanecen en la hoja horadándola.

El microhábitat conformado básicamente por plantas, constituye refugio para los organismos. Se encuentran varios tipos de macrófitas que dan lugar a este tipo de microhábitat húmedo:

Hidrófitos o micrófitos acuáticos en sentido estricto, aquellas plantas que tienen todas sus estructuras vegetativas sumergidas o flotantes. Se incluyen en este grupo a plantas vasculares, algunos géneros de briófitos y las algas carófitas y filamentosas. Se encuentran enraizados al sustrato o flotan libremente en el agua. Son los mejores indicadores del estado del hábitat, Potamogeton sp., Myriophyllum sp., Ceratophyllum dermesum, Lemna sp, Nymphaea sp.

Helófitos o plantas acuáticas de lugares encharcados con la mayor parte de su aparato vegetativo (hojas, tallos y flores) emergentes. Se localizan en los bordes de las lagunas, charcas y zonas inundables no muy profundas Phragmites sp., Typha sp., Schoenoplectus sp., Butomus sp.

Higrófitos o plantas de borde que se sitúan sobre suelos húmedos en los bordes de los humedales, y que suelen acompañar a los helófitos. Algunas especies de insectos acuáticos como los odonata, se fijan al tallo sumergido y emergen como pupa. Depredan a otros insectos y pequeños vertebrados. Otras especies de insectos acuáticos se alimentan de las raíces u hojas de estas plantas. Otras simplemente buscan refugio.

El microhábitat humu, se forma por efecto de las inundaciones que arrastran la materia orgánica, que se acumula sobre terrenos con depresiones, y vegetación que se descompone y forma un material de color oscuro. Las especies humícolas se encuentran en el interior de este material y sobre la superficie de otras partículas sólidas que se encuentran sobre ella.

El microhábitat madidu, lo encontramos en zonas de charcos y en orillas de otros cuerpos de agua de corriente muy leve o nula. Esta caracterizado por objetos orgánicos 
como ramas de árboles, fragmentos de madera y troncos, rocas y objetos inorgánicos (por la cercanía a centros poblados) como recipientes plásticos, material textil, envases metálicos (aluminio) y botellas de vidrio. Debajo de los objetos se acumula detritus que sirven como recursos alimenticios además de constituir refugio.

Las especies madícolas se localizan debajo de los objetos señalados, o sobre sus entornos húmedos (fisuras, hoyos, envoltorios, pliegues, etc.), o pueden estar sujetos al sustrato de fondo.

El microhábitat radix, se encuentra distribuido en las raíces de algunas plantas vasculares sobre cuerpos de agua de muy escasa profundidad, cercano a las orillas o sobre roca arenisca inundadas. En las raíces de Eichhornia, Utricularia, Salvinia, Paspalum y Pistia se alojan una variedad de especies de insectos acuáticos.

Las especies radíxicola se encuentran sumergidas o enterradas, entre el sustrato húmedo, del interior de la red formada por las raíces y se colectan al remover las raíces (Short \& García 2014).

El microhábitat ramentum está distribuido en los diferentes cuerpos de agua, la mayoría de corriente nula. Pero hay situaciones en que en algunas orillas de pequeñas quebradas que son muy arenosas, se observan las especies salir y nadar fuera de ella al ser removida. Las especies ramentumícolas, se encuentran enterradas o adheridas a los gránulos de la arena y se visualizan al remover dicho sustrato.

También se encuentra en las dunas inundadas y con algún tipo de vegetación acompañante. El detritus se acumula entre los poros o intersticios que forman los granos de arena sumergidos. Además representa algún tipo de refugio, contra depredadores y cambios bruscos de temperaturas, al encontrarse agua por debajo de la superficie.

En el microhábitat spaqua, se encuentran la mayoría de las especies de insectos acuáticos de dimensiones variables. Este medio les permite transportarse libremente por el fondo de los cuerpos de agua, que presentan profundidades no mayores a $100 \mathrm{~cm}$. Pueden trasladarse de un lugar a otro, mediante el nado, y utilizan el sustrato de fondo, como anclaje, mientras están en reposo. Suben a la superficie constantemente a respirar. La gran mayoría son especies depredadoras, que se alimentan de pequeños invertebrados. Incluso hasta en algunos casos de mayor dimensión que la de ellos mismos. Como el caso de Megadytes (Dytiscidae) y Belostoma (Belostomatidae), tanto la larva como el adulto, capturan pequeños peces y anfibios.
El microhábitat supaqua, representa otro medio de gran movilidad para las especies de insectos acuáticos, pero se trasladan por la superficie. Las especies se han adaptado a movilizarse en este medio, gracias a la utilidad de estructuras pubescentes hidrófobas en sus patas y su región ventral. Dichas estructuras repelen el agua, y al movilizarse dan la apariencia de resbalar, ya que no se rompe la tensión superficial. En su mayoría son depredadoras, de otras especies que accidentalmente caen al estanque por efecto de la acción del viento o por su propio vuelo.

El microhábitat ediscon, es característico de fuertes corrientes, rápidos, riachuelos y manantiales en los cuales tienden a originarse zonas de contención como restos de troncos, grandes y pequeñas rocas. Con la formación de galerías intersticiales, en las cuales se localizan las especies de insectos edisconicolas que se alimentan del detritus allí acumulado. Algunas especies son depredadoras y otras son omnívoras, además de resultar un buen refugio.

En el microhábitat petra, las especies petrícola (arácnidos e insectos), se desplazan al libre nado en los pequeños charcos, que se forman en las concavidades y depresiones de las rocas. En ambas condiciones ocurre la sedimentación de detritus. Unos se alimentan de este, mientras que otros, lo depredadores se alimentan de ellos. Es una competencia por la vida en espacios muy reducidos (García 2000).

Otros sólo se desplazan sobre las piedras cercanas a las fuentes de agua, porque depredan organismos que viven sobre ellas o que emergen del agua.

El microhábitat rabpet de rápidos y quebrada turbulentas, particularmente se encuentra en el fondo del cauce, donde la superficie rocosa es limpia pero con grietas y fisura sobre el plano. En el fondo del cauce, se encuentran rocas distribuidas sobre el sustrato de fondo. Se depositan sedimentos y detritus entre los intersticios que se forman entre las rocas sueltas y el sustrato rocoso. Las especies rapticolas pueden recolectarse, durante el período de sequía fuerte, cuando quedan al descubierto las rocas y se forman pozos, aquí encontramos rocas y piedras con intersticios. También sirven como refugio ante la fuerza y velocidad de arrastre de la corriente. Sin embargo a nivel de fondo, la velocidad de arrastre es menor que en la superficie de la corriente.

El microhábitat rabpet característico de rápidos quebradas fuertes. El sustrato áspero y pedregoso del fondo, permite a las especies de insectos que han desarrollado característica de fijación al medio. Ganchos y ventosas en larvas de dípteros, de plecópteros, de hemípteros y de coleópteros, y uñas fuertes como garras en larvas y adultos de 
Meru phillisae (Meruidae) y en especies de Torridincolidae, para fijarse y evitar ser arrastrados, por la corriente.

Las especies rabpetícola poseen otras adaptaciones como el cuerpo fuselado para presentar una resistencia mínima a la corriente; cuerpos aplanados, que les permite refugiarse entre los espacios disponibles.

El microhábitat raupet, se forma en los rápidos, a medida que baja por la pendiente. En algunos lugares se angosta el cauce y la violencia que despide el agua al bajar con fuerza, golpea fuertemente las rocas a su paso.

Las rocas que se encuentran a los lados del cauce sobre las orillas, y que sobresalen por encima del nivel del cauce, son erosionados. Se crea una superficie áspera que permite la adherencia de plantas vasculares, tanto debajo, en el fondo, como arriba, por encima de la superficie.

Las especies raupetícolas, se adhieren a los sustratos como rocas, plantas vasculares acuáticas y cualquier objeto sumergido en la corriente. El flujo de la corriente puede ser variable. La larva y el adulto habitan, el área erosiva de la corriente de agua, donde el sustrato vegetal retiene la abundante materia orgánica fina en suspensión, lo que representa el alimento principal de las larvas y adultos.

El microhábitat caulae, es particular de las pequeñas quebradas con mucho cauce. El agua va erosionando las orillas en forma horizontal, creando pequeños hoyos u oquedad, que se inundan frecuentemente. A medida que el agua baja su nivel, se deposita detritus, que es retenido por la presencia de raíces y microalgas, que se adhieren a las paredes del hoyo. Creando un ambiente propicio para especies muy pequeñas de insectos acuáticos y algunos arácnidos como los ácaros acuáticos.

El tercer grupo de microhábitats se encuentran asociados al sistema manto residual del corredor ribereño (Grupo C).

Un solo microhábitat en este sistema, el folia decidunt. El manto de hojarasca, a nivel de los pequeños cuerpos de agua, en la zona boscosa, propicia la formación del microhábitat húmedo. Es importante destacar, que estos pequeños cuerpos de agua son temporales. Durante el periodo de sequía conservan ciertos niveles de humedad, que favorece la presencia de una serie de organismos entre ellos insectos acuáticos y semiacuáticos. Las especies folícolas se adaptan a vivir entre la humedad del manto de hojarasca. La descomposición del material orgánico atrae a muchas especies incluyendo especies no acuáticas.

A nivel de los ríos la hojarasca es arrastrada por la corriente. Con tendencia a acumularse en el fondo somero del margen ribereño, donde la velocidad de la corriente disminuye, sedimentando el material vegetal. Las espe- cies folicolas se encuentran entre las capas sedimentadas, la cual contiene espacios intersticiales.

El cuarto grupo está integrado por un microhábitat dual y está asociado al sistema de escorrentía del corredor ribereño (Grupo D).

En el microhábitat higropétrico, algunas especies de insectos higropetrícolas se encuentran fuertemente fijadas al sustrato rocoso, donde la fuerza de la corriente es algo menor que en la superficie (Short et al. 2015). Otras pueden moverse libremente en la débil escorrentía y otros se mantienen adheridos (Short et al. 2015). En los dos casos donde se presenta el microhábitat, el detritus suelen acumularse en los espacios donde la corriente es menor a casi nula, lo que permite su asimilación, por parte de los organismos.

El microhábitat ha sido muy poco estudiado, su ubicación en lugares de difícil acceso y lo resbaladizo del sustrato rocoso, posiblemente contribuyan, pero quizás la causa mayor sea el desconocimiento de las especies que lo habitan. Los trabajos más destacados en la recolección de especies de coleópteros higropetrícolas se encuentran en Short y García (2010), Clarkson y Short (2012) y Short et al. (2013) en Suramérica.

Un quinto grupo es un microhábitat muy particular y está asociado a un sistema termal (Grupo E).

El microhábitat Termali y su sistema termal, son estructuras ecológicas, que difieren del resto de los sistemas y microhábitat. El factor delimitante aquí es la temperatura. Hay muy pocos estudios sobre los medios termales donde habiten insectos, solo una especie termalícola de la familia Hydrophilidae (Enochrus sp.) en esta investigación. El hábitat es un pequeño manantial sulfuroso que brota del suelo, formando una pequeño charco o pozo. La especie termalícola fue capturada sobre la orilla caliente del cuerpo de agua. Los ejemplares, nadaban libremente desde el fondo hasta la superficie.

Un sexto grupo de microhábitat está asociado al sistema Troglobio (Grupo F).

El grado de adaptación al medio hipogeo es variable. Algunas especies completan su ciclo de vida en el interior de las cavernas, pero pueden también poblar otros medios y no son exclusivos de ellas (troglófilos) mientras que otras especies sólo los habitan de forma temporal o incluso accidentalmente (troglóxenos) (Jeannel \& Racovitza 1918).

El séptimo grupo de microhábitats se asocia al sistema fitotelmata del corredor ribereño (Grupo G)

El microhábitat atrix es característico de las plantas monocotiledóneas. Estas guardan un centro cóncavo, lla- 
mado atrio, un espacio tipo tanque (Balke et al. 2008). Este atrio acumula agua durante las épocas de lluvia y las conserva durante la época de sequía. Es un medio apropiado para especies que buscan estar separados del suelo. Este microhábitat es muy utilizado por muchas especies de invertebrados y pequeños vertebrados. Las bromelias son el grupo de planta que mejor provee este tipo de ambiente natural.

El microhábitat axis es característico de muchas plantas monocotiledóneas que presentan hoja anchas y superpuestas. El espacio que existe entre hoja y hoja es la axila y puede variar dependiendo de la especie. Puede acumular agua durante la época de lluvia y conservarla durante el verano. Dicho espacio es utilizado como refugio por un número de especies y la acumulación de detritus sirve como recurso alimenticio a las especies axícolas. Las bromelias en su mayoría proveen este tipo de microhábitat. Los palmares y algunas musaceae como Musa sp. (Plátano), también presentan esta particularidad de microhábitat.

Los estudios que se han realizado sobre las comunidades animales, que viven en el interior de las bromelias han aportado altos valores de diversidad. Por ejemplo, Beuteispacher (1999), encontró 47 familias de insectos pertenecientes a 14 órdenes en una única especie, Aechmea bracteata (Swartz) Griseb.

Estos particulares lagos en miniatura, considerados como hábitats inestables y temporales (Williams \& Feltmate 1992), albergan una fauna muy diversa y especializada por darse allí las condiciones especiales para su supervivencia. Dentro de cada espacio interfoliar ocupado por agua y materia orgánica podemos reconocer una estratificación característica de sus componentes. En la parte basal de las hojas más externas se localizan detritos muy finos entre los que podemos encontrar otras especies de animales incluyendo insectos de hábito terrestre. Encontramos coleópteros (Carabidae, Curculionidae, Staphylinidae), Dermaptera, Pseudoescorpiones, Scorpionidae, Miriapoda, Orthoptera y larvas de algunos dípteros como Stratiomyidae. También Anfibios, Reptiles y Anélidos.

Un segundo nivel está constituido por hojarasca y detritos aún no degradados, sumergidos la mayor parte del tiempo en el agua. En esta zona son frecuentes entre los detritos las larvas de dípteros (Syrphidae, Culicidae, Tipulidae, Chironomidae, Drosophilidae, Tabanidae), larvas de coleópteros, ninfas de cucarachas, libélulas (en hojas más interiores con menos materia orgánica), así como orugas de mariposa de hábitos semiacuáticos y los principales degradadores de la materia orgánica, los crustáceos Isópoda (Beuteispacher 1999).
Otro microhábitat de este grupo el spathis, es característico de las monocotiledóneas donde la bráctea se encuentra muy especializada, formando cavidades que acumulan agua durante el invierno y lo conservan durante el verano. El espacio húmedo propicia el desarrollo de especies de insectos spathisícolas. La cavidad acumula materia orgánica en descomposición, que sirve de alimentos a larvas y adultos, además de ofrecer refugio contra el medio circundante. Las Heliconiaceae como las aves del paraíso son plantas que presentan este tipo de microhábitats.

El xilonaq es otro microhábitat fitotelmata que mantiene la humedad del medio. Se presenta en los desechos vegetales, como troncos en descomposición, concavidades en la médula del tronco con agua acumulada en la base, que propician un ambiente blando y suficiente alimento. Las especies xilonaquícolas, viven en el interior del tronco y sobrenadando en el contenedor de agua.

A menudo la fauna asociada a los hábitat fitotelmata resultan ser únicos o endémicos (Balke et al. 2008).

El sistema morichales del corredor ribereño forma el octavo grupo de microhábitat (Grupo H).

El moriche es el microhábitat característico de este sistema. El microhábitat se encuentra diseminado por todo el conglomerado del morichal. Pero no como un solo microhábitat, sino como un conjunto de microhábitats que se encuentran diseminados por el corredor ribereño, En un morichal están presentes los diferentes microhábitats que hasta el momento ha sido posible identificar en esta investigación.

Los morichales son pruebas fehacientes de la diversidad que puede surgir de diferentes microhábitats reunidos en un mismo lugar. Este sistemas, dominados por la palma moriche o canangucho (Mauritia flexuosa), están por lo general asociados a cuerpos de agua permanentes que pueden ser ejes de drenaje definidos o ambientes inundados estacionalmente (Blanco-Belmonte 2013). Las características fisicoquímicas de sus aguas (claras y/o negras), unidas a los suelos y a la geomorfología por donde discurren, así como aspectos propios de su historia natural, le confieren a estos ambientes una fragilidad enorme (Blanco-Belmonte 2013).

Los microhábitats Anpógenos como los sistemas de riego artificial, tanto en regiones rurales y urbanas áridas pueden crear ambientes de agua dulce que son adecuados para las formas inmaduras de una variedad de insectos acuáticos anpogenícolas.

La agricultura y la ganadería, y la productividad de las tierras agrícolas se han mejorado con la implementación de los sistemas de riego alimentado por ríos, red 
de acequias de riego y drenaje, y los volúmenes de agua son controlados por apertura y cierre de zanjas. Burroni et al. (2004), clasifica los ambientes acuáticos de actividad antropogénica en cuatro categorías: cuerpos de agua temporales, cuerpos de agua semipermanentes, acequias y zanjas de drenaje.

Lagunas construidas con sentidos recreativos, fuentes luminosas en parques y plazas, representan un área de colonización por parte de aquellas especies de insecto que han logrado adaptarse a los cambios ecológicos producidos por el hombre, sobre todo en épocas de apareamiento y reproducción.

En la clasificación habitalógica de los microhábitats húmedos, el hábitat mayor o el supra sistema, encierra todas las aguas dulces continentales (véase esquema 1 ). A su vez está constituido por un conjunto de muchos humedales de agua dulce. El término humedales se refiere a una amplia variedad de hábitats interiores (agua dulce), costera y marina que comparten ciertas características. Generalmente se los identifica como áreas que se inundan temporalmente, donde el agua subterránea aflora en la superficie o en suelos de baja permeabilidad cubiertos por agua poco profunda (Ramsar 1989).

La convención de Ramsar (1989), clasifico a más de treinta humedales naturales y nueve artificiales. Entre estos humedales, sólo los de agua dulce son de interés para esta investigación. Estos humedales de aguas dulces (ribereñas, lacustres, palustres y artificiales), entre otros, representan la base del supra sistema, es decir, las aguas dulces continentales. Un humedal en sí, representa un hábitat o un sistema que conforman cuerpos de agua de dulce. El súper sistema que es el humedal en sí, representa los cuerpos de agua ya existentes de agua dulce como los lagos, lagunas, ríos, rápidos etc. En los cuales se diversifican los microhábitat identificados en esta investigación.

\section{1) Asociaciones de microhábitat}

Los subsistemas léntico y lótico no se encuentran separados ni son específicos (véase esquema 1). El subsistema lótico sufre transformaciones o cambios durante su existencia. Está estrechamente enlazados a los cambios climáticos. En época lluviosa puede existir como un inmenso remanso o un pequeño rápido. Pero en época de verano, tiende a disminuir su fortaleza.

Con el tiempo disminuye su cauce o forma estructuras meándricas, que lentifican cuantitativamente la fuerza de la corriente. Al disminuir el cauce forma extensas riberas abiertas, dejando charcos y pozos en su trayecto.
Los meandros y la disminución del cauce, se convierten en espacios húmedos. No hay movimiento de arrastre por la corriente, dando lugar así al subsistema léntico. La colonización por los insectos se realiza gradualmente, dependiendo de la disponibilidad de alimentos y la época de reproducción. Por tanto podemos decir que los subsistemas lénticos se originan a partir de los subsistemas lóticos.

Por ejemplo, un río a medida que disminuye su cauce, va formando pequeños pozos o charcas. Sobre estos pequeños cuerpos de agua, hay acumulación de hojarasca (folia decidunt) y pequeños bancos de arena (ramentum). En los bordes se producen sedimentos (caenum) entre otros, estamos hablando de al menos tres microhábitats, alrededor en un medio léntico, que a su vez forma parte de un sistema de agua en movimiento.

Se encontró ramentum muy cercano a ediscon y a folia decidunt. En otras situaciones se encontró higropetrico y folia decidunt. Lo que se quiere decir, es que los microhábitat no son particulares de un solo ambiente.

En un subsistema lótico se encontró que existían espacios lénticos, como el ramentum en los márgenes de ríos y folia decidunt y así sucesivamente.

Algunas especies de escarabajos del genero Oocyclus (Hydrophilidae), fueron encontrados en microhábitat higropetrico. Pero también fueron encontrados enterrados en el ramentum de suaves corrientes (Short \& García 2010a).

En los siguientes artículos: (García 2000abcde, 2001, 2002ab, 2007, 2008, 2009); (García \& Navarro 2001); (García et al. 2012); (Short \& García 2007); (Short et al. 2010); (Short \& García 2010); (Short et al. 2012); (Balke et al. 2008); (Short et al. 2013); (Short \& García 2014); (Short et al. 2015); (Alarie et al. 2011); (Spangler 1972); (Miller \& Spangler 2008); (Miller \& Wheeler, 2008); (Miller \& García 2011); (Gustafson \& Miller 2012); (Miller 2009); (Miller 2013), al igual que muchos trabajos más, no se describe el microhábitat ideal de las especies recolectadas. Solo nombran los hábitats clásicos hasta entonces, léntico y lótico, sin especificar el verdadero hábitat de las especies. Esta investigación demuestra que los sistemas limnicos pueden ser muy extensos y presentar muchas variaciones logísticas.

Los microhábitats húmedos, se encuentran distribuidos a lo largo de los corredores ribereños o de los humedales que los contiene. En su mayoría se originan por efecto de grandes crecidas e inundaciones y por lluvias temporales. Particularmente algunos microhábitat son temporales. 
Al igual que los microhábitat naturales, los microhábitats Anpógenos, cuyo origen es debido a la actividad antropogénica agropecuaria y cultural. También están presentes las asociaciones, debido a que los microhábitat antpógenos, son los mismos microhábitats que existen en la naturaleza. Por ejemplo, el cultivo del arroz, necesita de grandes extensiones de terrenos, los cuales son inundados por determinado tiempo. En ese tiempo se desarrollan microhábitats como el hercircum, spaqua y supaqua. Estos tres microhábitat, ocurren en el mismo lugar, y se diferencia por el aspecto morfológico y el tipo de especies que hacen vida en ellos.

Por otro lado un subsistema léntico, puede dar origen a un subsistema lótico. Es decir, pasar de la inamovilidad a la velocidad de arrastre del agua. Este caso se puede visualizar, en lagos y lagunas, que por acción de las precipitaciones en invierno, aumenta de nivel, y produce un punto de desagüe. Sobre este punto, las masas de agua, desbordan según la pendiente, originando rápidos y quebradas. Por un determinado tiempo, mientras dura el invierno.

Al final, este subsistema lótico creado a partir de un subsistema léntico, nuevamente dará origen a un sistema léntico, a medida que la corriente va cesando, formando charcas, pozos y otros cuerpos de agua. Las lagunas de origen periglaciar de las montañas andinas, son subsistemas lénticos y están constantemente formando microhábitats lóticos dentro de un subsistema lótico.

\section{2) Superposición de microhábitats}

Los microhábitats pueden, en ciertos momentos ocultarse tras un camuflaje no definido. Un banco arenoso (ramentum) podría encontrarse bajo un montón de hojarasca (folia decidunt), y las especies presentes no necesariamente vivan en el folia decidunt, o viceversa. Sin embargo, podría tratarse de especies asiduas.

Las especies son las que permiten identificar los microhábitat como tal y para eso debemos reconocer completamente el lugar de recolección. Para apartar todas las variables posibles, que puedan confundir la procedencia exacta de los ejemplares, es necesario muestrear las áreas que aparentan similitud. El hecho que recolectemos ejemplares en lugares determinados que presentan las mismas características, es una prueba de la atracción de las especies por ciertas condiciones.

Hay especies que son específicos de cierto tipo de microhábitat. Algunos solo son encontrados en los bancos de arena (ramentum), medio sumergida algunos centímetros en la orilla de un cuerpo de agua. Este ambiente es encontrado en una gran variedad de cuerpos de agua, en los sistemas ambientales.

García (2002a) identifica 12 especies del género Andonectes en un parque de recreación (Los Chorros de Milla) en el Estado de Mérida, Venezuela, recolectados en diferentes microhábitats pero muy cercanos entre sí.

Unos ejemplares fueron recolectados enterrados en ramentum, otros fueron recolectados en el folia decidunt de un pequeño charco, y otros fueron recolectados en el glarea, a lo largo de una pequeña corriente de agua. En el mismo estado andino, hacia el sur, (la Azulita) se recolectaron ejemplares de Andonectes, entre las piedras de la pared vertical, de un pequeño salto, un microhábitat higropetrico. En otra localidad (Laguna de Aguas Negras) de la región andina Edo. Trujillo, Venezuela, se recolectaron ejemplares del mismo género, nadando libremente en el spaqua. Y en otra localidad de la misma región andina, se recolectaron ejemplares enterrados en el humu de un fango lodoso y otros en el radix de plantas vasculares en la orilla de una laguna (Laguna el Cedro).

Las especies de insectos pueden estar distribuidas, en un área enmascarada. Dos o más microhábitat, pueden estar superpuesto, aparentando uno. Se superponen a simple vista, como el raupet, higropétrico y petra.

Las especies higropetrícolas se encuentran en la zona donde la roca se mantiene constantemente húmeda, alejado de la fuerza del raudal. En la zona seca de la roca donde la humedad no es constante, se mueven algunas especies petrícolas, generalmente depredadoras. En la zona donde el raudal golpea la roca y se encuentra sustratos vegetales como Podostemaceae (plantas vasculares acuáticas) (Villamizar et al. 2011), se encuentran las especies raupetícolas.

\section{3) Diversificación y distribución de las especies de in- sectos acuáticos en los humedales}

Merritt et al. (1984), Vodopich y Cowell (1984), Ward (1992), Wallace y Webster (1996), Vinson y Hawking (1998), Medianero y Samariano (2004), entre otros, plantean que bajo condiciones naturales, la diversidad y la distribución de los insectos en los humedales, está determinada por una serie de factores o variables como el tipo de sustrato, hábitat, luz, alimento, química del agua, oxígeno disuelto, temperatura, patrones de corriente, altitud, ancho del río, vegetación ribereña y factores regionales como latitud y continentalidad. Sin embargo, si convertimos a estas variables o factores como simples eventos que forman parte de una variable o factor más complejo, es decir, la suma de las variables anteriores, daría lugar a 
una variable más compleja como el hábitat propiamente dicho. El estudio habitalógico demuestra que tanto el sustrato, la luz, el alimento, la vegetación ribereña, la altitud y los patrones de corriente determina el hábitat de los individuos, por adaptarse a las condiciones que les provee ese medio, entonces porque el hábitat sería una variable simple y no la suma de todos ellos. No debemos verlos por separados sino como una sola variable muy compleja a partir de varios factores del medio, sin despreciar a cada uno de ellos por separado.

Desde el punto de vista de la habitalogía, un espacio natural se convierte en hábitat, desde el momento que los organismos la ocupan. Esto significa que cualquier espacio natural, no necesariamente representa un hábitat. Los espacios naturales están sujetos a cada una de las variables o factores nombrados anteriormente. En este momento, ese espacio natural representa un factor más, o un variable más, pero aun no es un hábitat. Cuando los organismos lo encuentran aprovechable, lo ocupan y con él todas las variables naturales, en este momento, todas las variables representan el hábitat para ese organismo.

En casos excepcionales las planicies de inundación se deben a accidentes geográficos y algunas, como por ejemplo, el delta del río Orinoco, son extensamente pantanales. En las planicies existen muchas masas de agua que varían desde los estanques temporales hasta grandes lagunas y pantanos permanentes.

La actividad humana puede propiciar la colonización de nuevos nichos, en sus ambientes culturales, exceptuando aquellos donde no puede copiar su naturaleza como los microhábitats termali, trogli y moriche (véase esquema 1 ).

Las comunidades acuáticas vivas residentes se mantienen relativamente estables, aunque puede haber influjos de especies visitantes al cambiar las condiciones en otras partes del sistema. Los cambios estacionales de ríos, se deben a variables climáticas, la más importante es la temperatura. Aunque la duración del día también puede tener importancia. La temperatura depende principalmente de la latitud, con una variación anual que aumenta al crecer la distancia del ecuador (Welcomme 1980).

La vegetación superior generalmente se limita a algunas formas resistentes adheridas a las rocas húmedas, especialmente en las aguas mansas más protegidas. La microflora y fauna pueden formar un sustrato en el fondo de un rabión. Hay también muchas especies de insectos adaptadas a la vida en el fondo donde se refugian en las rocas o se sujetan a ellas.

La materia alóctona, que pueda caer en el agua, desde los árboles o hierbas vecinos, forman una masa que constituye la base de una de las cadenas alimentarias principales, algo muy bien aprovechado por las especies supaquícolas.

Cuando baja el nivel del agua de los ríos disminuye la tensión del oxígeno disuelto, muchas formas larvarias no sobreviven, por lo que están presentes otras adaptaciones para la recolonización cuando reaparecen condiciones más favorables.

AGRADECIMIENTOS. Agradezco la realización de esta investigación a la Dra. Melva García por apoyarnos con la logística en el estado Apure, al señor Manuel Echenique por su colaboración al permitirnos la utilización de su finca en el estado Apure, a Jesús Camacho curador del Maluz de la universidad del Zulia, por compartir y apoyar horas de campo en varias excursiones y al Dr. Andrew Short por permitirnos utilizar nuestro banco de fotografía registrado de su proyecto en Venezuela, sobre los cuales figura la base de esta investigación.

\section{LITERATURA CITADA}

Alarie, Y., Short, A. E., García, M. \& Joly, L. J. 2011. Larval Morphology of Meruidae (Coleoptera: Adephaga) and Its Phylogenetic Implications. Annals of the Entomological Society of America, 104: 25-36.

Balke, M., Gómez-Zurita, J., Ribera, I., Viloria, A., Zillikens, A., Steiner, Jr., García, M., Hendrich, L. \& Vogler, A. P. 2008. Ancient associations of aquatic beetles and tank bromeliads in the Neotropical forest canopy. Proceedings of the National Academy of Sciences, 105: 6356-6361.

Beuteispacher, C. R. 1999. Bromeliáceas como ecosistemas. Con especial referencia a Aechmea bracteata (Swartz) Griseb. Ed. Plaza y Valdés, México, 123 pp.

Blanco-Belmonte, L. 2013. Insectos acuáticos asociados a tres ríos de morichal de los llanos orientales, cuenca del Orinoco, Venezuela. Capítulo 9. Pp. 165-180. In: Lasso, C. A., A. Rial y V. GonzálezB. (Edit.). VII. Morichales y Canangunchales de la Orinoquia y Amazonia: Colombia-Venezuela. Parte I. Serie Edit. Rec. Hidrob. y Pesq. Cont. de Colombia. Inst. de Invest. de Rec. Biol. Alexander von Humboldt (IAvH). Bogotá, D. C., Colombia.

Burroni, N., Loetti, V., Freire Jensen, O. \& Schweigmann, N. 2004. New record and larval habitats of Culex eduardoi (Diptera: Culicidae) in an irrigated area of Patagonia, Chubut Province, Argentina. Memorias do Instituto Oswaldo Cruz, Rio de Janeiro, 99: 1-3.

Frissell, C. A., Liss, W. J., Warren, C. E., Hurley \& M. D. 1986. A hierarchical framework for strem habitat classification: Viewing strem in a watershed context. Environmental Management, 10: 199-214.

Clarkson, B. \& Short, A. E. 2012. Revision of the Oocyclus Sharp of Brazil with description of ten new species (Coleoptera: Hydrophilidae: Laccobiini). Zootaxa, 3183: 1-35.

García, M. 2000a. Four new species of Chasmogenus Sharp, 1882 (Coleoptera: Hydrophilidae: Hydrophilinae) from Venezuela. [Spanish]. Boletín del Centro de Investigaciones Biológicas, 34: 45-58. 
García, M. 2000b. A new species of Quadriops Hansen, 1999 (Coleoptera: Hydrophilidae: Hydrophilinae) from Venezuela. [Spanish] Boletín del Centro de Investigaciones Biológicas, 34: 59-65.

García, M. 2000c. Two new genera and three new species of aquatic Coleoptera (Hydrophilidae: Hydrophilinae) from Venezuela. [Spanish]. Boletín del Centro de Investigaciones Biológicas, 34: 221-236.

García, M. 2000d. Three new species of Helobata Bergroth 1888 (Hydrophilidae: Hydrophilinae) from Venezuela. [Spanish]. Boletín del Centro de Investigaciones Biológicas, 34: 237-246.

García, M. 2000e. Two new species of Notionotus Spangler, 1972 (Coleoptera: Hydrophilidae: Hydrophilinae) from Venezuela, and new records for $N$. rosalesi and $N$. liparus. [Spanish]. Boletín del Centro de Investigaciones Biológicas, 34: 247-258.

García, M. \& Navarro, E. 2001. Description de Notaticus obscurus (Coleoptera: Dytiscidae: Aubehydrini), a new species of aquatic beetle in the east and a new registration for Notaticus fasciatus in the south of Venezuela. Boletín del Centro de Investigaciones Biológicas, 35:142-150.

García, M. 2001. New Colymbetinae (Coleoptera, Dytiscidae) from southern Venezuela. Boletín del Centro de Investigaciones Biológicas, 35: 339-347.

García, M. 2002a. Nuevos Escarabajos Chaetarthriini (Coleoptera; Hydrophilidae; Hydrophilinae) de los Llanos de Apure, región Sur Occidental de Venezuela. Boletín del Centro de Investigaciones Biológicas, 36: 185-204.

García, M. 2002b. El Genero Andonectes Guéorguiev, 1971 (Coleoptera; Dytiscidae), Descripción de doce nuevas especies en Venezuela. Boletín del Centro de Investigaciones Biológicas, 36: 307-330.

García, M. 2007. Coleópteros Acuáticos (Insecta: Coleoptera) del Estado Apure, Venezuela. Boletín del Centro de Investigaciones Biológicas, 41: 255-264.

García, M. 2008. Especies de Coleópteros Ribereños (Insecta: Coleoptera) en Venezuela. Boletín del Centro de Investigaciones Biológicas, 42: 255-268.

García. M. 2009. Nuevos Bidessini del género Anodocheilus Babington (Coleoptera: Dytiscidae) de Venezuela, Anartia, (22): 1-10 pp.

García, M., Benetti, C. J. \& Camacho, J. 2012. A new species of Suphisellus Crotch, 1873 (Coleoptera: Noteridae) from "Los Llanos”, Venezuela. Zootaxa, 3298: 62-68.

Gustafson, G. T. \& Miller, K. B. 2012. A New species of Desmopachria Babington from Venezuela (Coleoptera: Dytiscidae: Hydroporinae: Hyphydrini), Koleopterologische Rundschau, 82: 71-76.

Hutchinson, E. 1967. A treatise of Limnology. II. Introduction to lake biology and the Limnoplankton. New Cork, John Wiley \& Sons, Inc., 1115 pp.

Jeannel, R. \& Racovitza, E. 1918. Enumeration des grottes visitées (1913-1917), 6e série. Biospeologica. Archives de zoologie expérimentale et générale, 57: 203-470.

Merritt, R. W., Cummins, K.W. \& Barton, T. 1984. The role of aquatic insects in the processing and cycling of nutrients, pp. 13-154. In: Merritt, R. W. \& Cummins, K. W. (Eds). Ecology of aquatic insects. Kendall/Hunt Publishing Co. EU.

Medianero, E. \& Samaniego, M. 2004. Comunidad de insectos acuá- ticos asociados a condiciones de contaminación en el río Curundú, Panamá. Folia Entomologica Mexicana, 43: 279-294.

Miller, K. B. \& Wheeler, Q. D. 2008. A new species of Agaporomorphus Zimmermann from Venezuela, and a review of the A. knischi species group (Coleoptera: Dytiscidae: Copelatinae). Zootaxa, 1859: 63-68.

Miller, K. B. \& Spangler, P. J. 2008. Fontidessus Miller y Spangler, a new genus of Bidessini from Venezuela (Coleoptera: Dytiscidae: Hydroporinae) with three new species. Zootaxa, 1827: 45-52.

Miller, K. B. 2009. On the Systematics of Noteridae (Coleoptera: Adephaga: Hydradephaga): Phylogeny, description of a new tribe, genus and species, and survey of female genital morphology. Systematics and Biodiversity, 7: 191-214.

Miller, K. B. \& García, M. 2011. Spanglerodessus shorti and Incomptudessus camachoi, new genera and species of Bidessini from Guyana and Venezuela. Zootaxa, 2996: 49-56.

Miller, K. B. 2013. Notomicrus josiahi, a new species of Noteridae (Coleoptera) from Venezuela. Zootaxa, 3609: 243-247.

Secretaria de la Convención de Ramsar. 2013. Manual de la Convención de Ramsar: Guia a la Convención sobre los Humedales (Ramsar, Irán, 1971), 6ta. Edición. Secretaría de la Convención de Ramsar, Gland (Suiza).

Short, A. E. Z. \& García, M. M. 2007. Tobochares sulcatus, a new genus and species of water scavenger beetle from Amazonas State, Venezuela (Coleoptera: Hydrophilidae: Hydrophilini). Aquatic Insects, 29: 1-7.

Short, A. E. Z., Joly, L. J. \& García, M. 2010. Discovery of the skiff beetle genus Yara Reichardt and Hinton (Coleoptera: Myxophaga: Hydroscaphidae) in Venezuela, with description of a new species. Coleopterist Bulletin, 64: 151-156.

Short, A. E. Z. \& García, M. M. 2010. A review of the Oocyclus Sharp of Venezuela with description of twelve new species (Coleoptera: Hydrophilidae: Laccobiini), Zootaxa, 2635: 1-31.

Short, A. E. Z., Alarie, Y., García, M. \& Joly, L. J. 2012. Are noterids specialized meruids (Coleoptera, Adephaga)? A reply to Dressler et al. Systematic Entomology, 1365-3113 pp.

Tansley, A. J. 1935. The use and abuse of vegetation concepts and terms. Ecology, 16: 284-307.

Short, A. E. Z., Greene, L. \& García, M. 2013. New species and new records of the hygropetric water beetle genus Oocyclus Sharp from South America (Coleoptera: Hydrophilidae). Zootaxa, 3741: 349-358.

Short, A. E. Z. \& García, M. 2014. A new genus of egg case-carrying water scavenger beetle from the Guiana Shield (Coleoptera: Hydrophilidae: Acidocerinae). Zootaxa, 3835: 251-262.

Short, A. E. Z., Joly, L. J., García, M., Wild, A. L., Bloom, D. D., Maddison, D. R. 2015. Molecular phylogeny of the Hydroscaphidae (Coleoptera: Myxophaga) with description of a remarkable new lineage from the Guiana Shield. Systematic Entomology, 40: 214-229.

Spangler, P. J. 1972. A new genus and two new species of madicolous beetle from Venezuela (Coleoptera: Hydrophilidae). Proceedings of the Biological Society of Washington, 85: 139-146.

Vinson, M. \& Hawking, C. 1998. Biodiversity of stream insects: variation at local, basin and regional scales. Annual Review of Entomology, 43: 27-293. 
Voshell, J. R. \& Simmons, G. M. 1984. Colonization and succession of benthic macroinvertebrates in a new reservoir. Hydrobiologia, 112: 27-39.

Villamizar, N., Cortez, J., Alarcón, O., Escalona, M., Escalona, C., Botto, C., Grillet, M. E. 2011. Primera descripción del hábitat acuático de Simulium guianense s.l. (Diptera: Simulidae) en el área endémica de oncocercosis, al sur de Venezuela. Boletín de Malariología y Salud Ambiental, Vol. LI, Nº 1.

Vodopich, D. \& Cowell, B. 1984. Interaction of factors gover- ning the distribution of a predatory aquatic insect. Ecology, 65: 39-52.

Wallace, J. B. \& Webster, J. R. 1996. The role of macroinvertebrates in stream ecosystem function. Annual Review of Entomology, 41: 115-139.

Welcomme, R. L. 1980. Cuencas Fluviales, Fao, Doc., Téc. Pesca, (202): 62.

Williams, D. D. \& Feltmate, B. W. 1992. Aquatic insects. C.A.B. International, UK. 358 pp.

\section{ANEXOS}

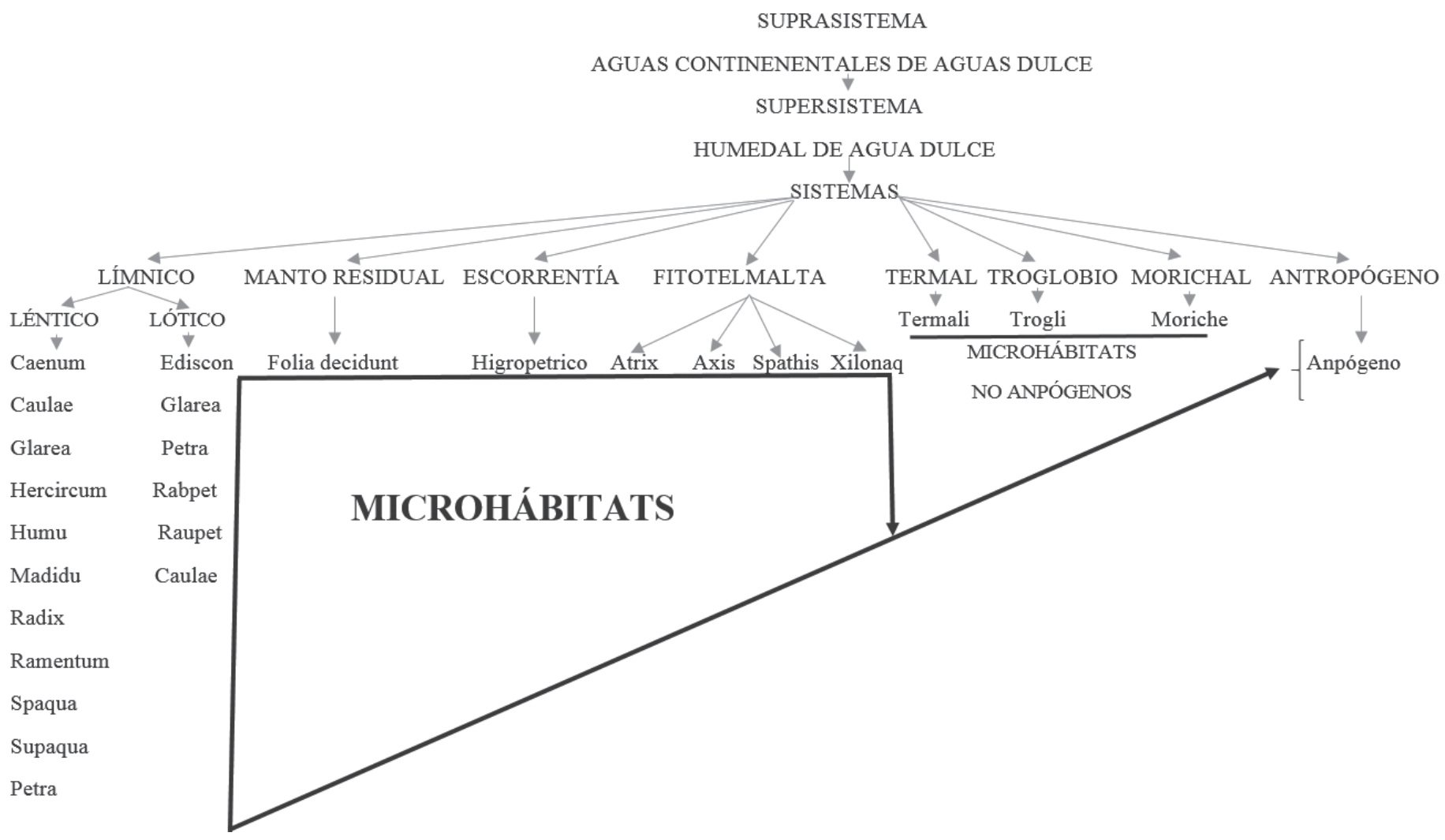

Esquema 1. Esquema clasificatorio de los microhábitat de agua dulce. 

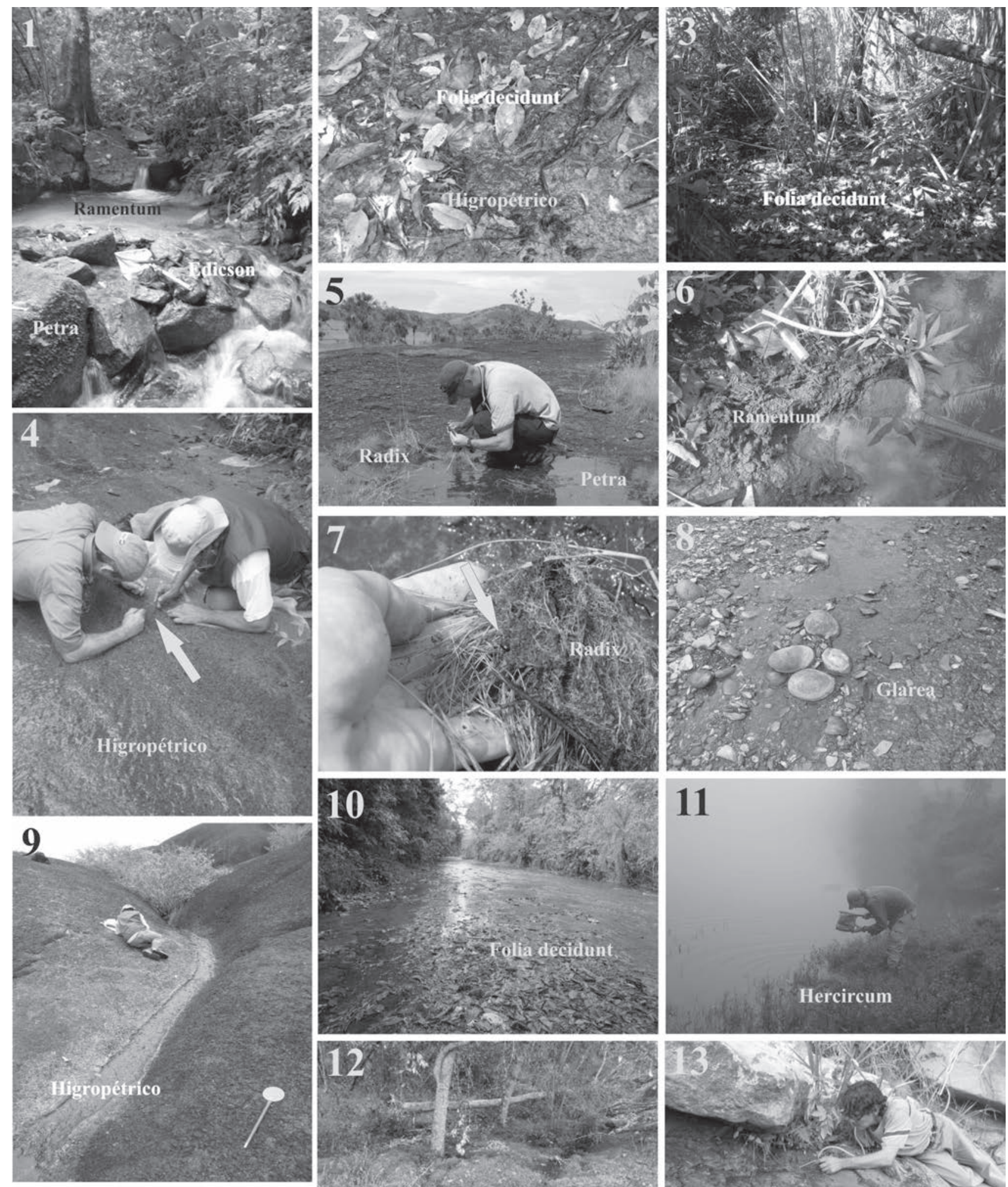

\section{Microhábitats}
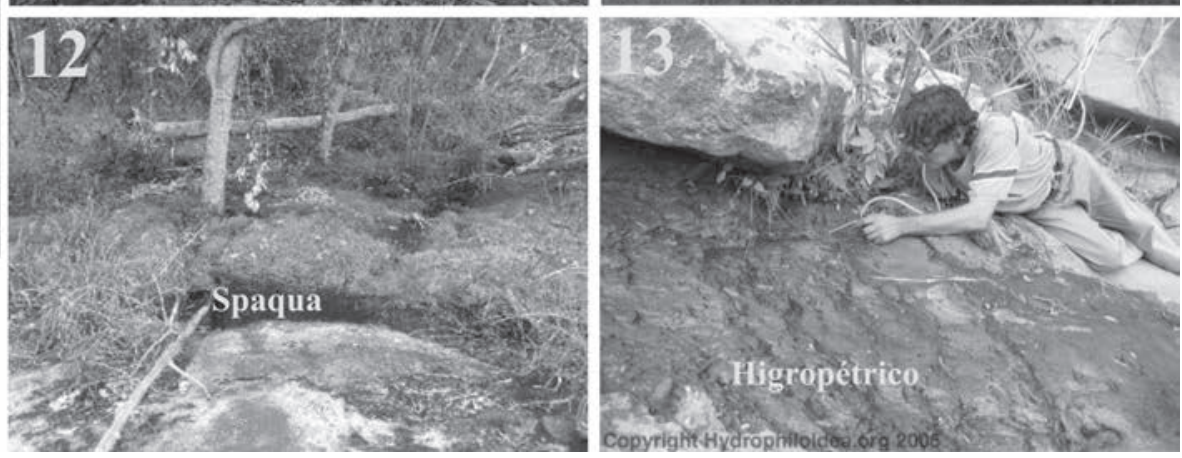

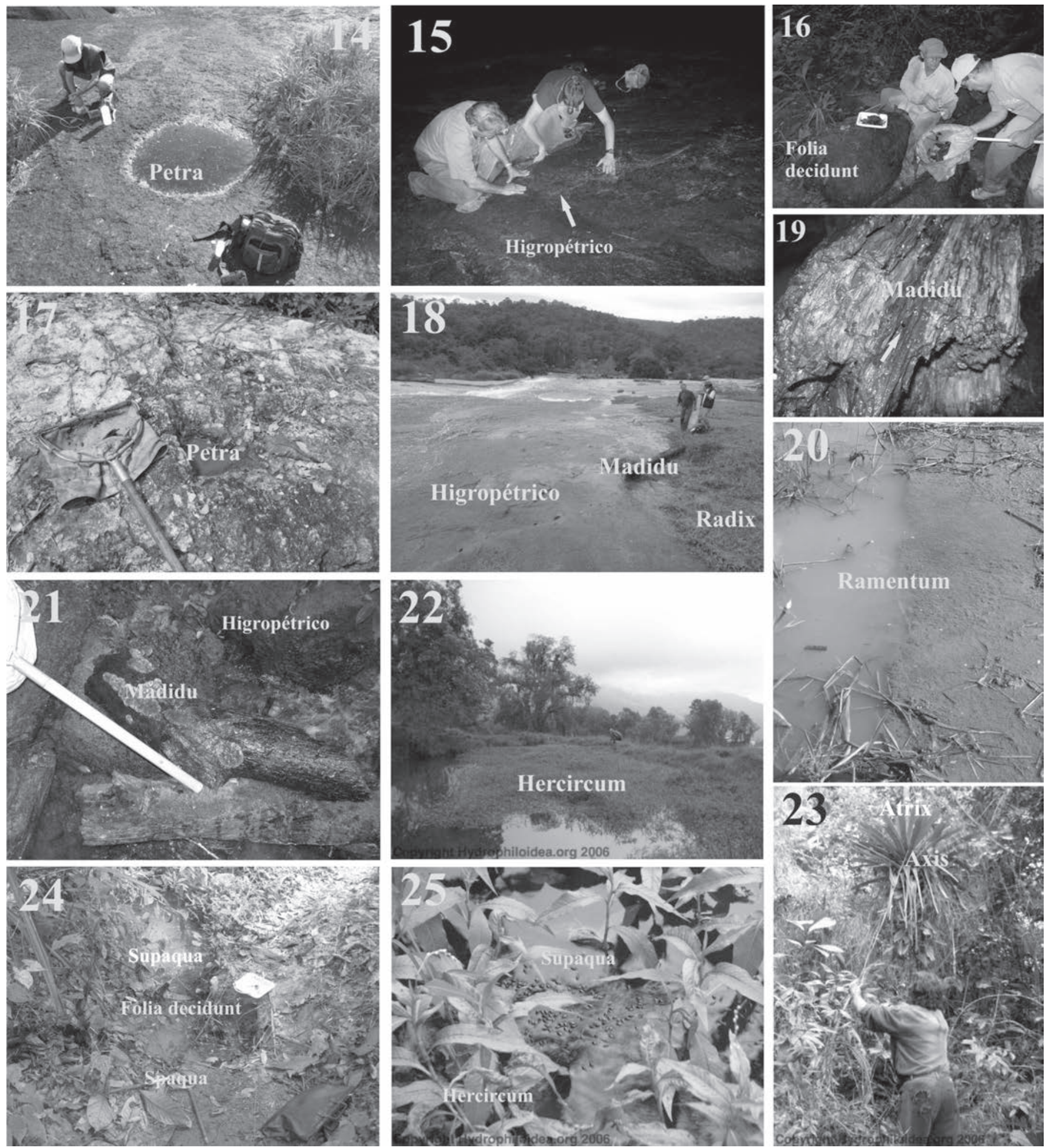

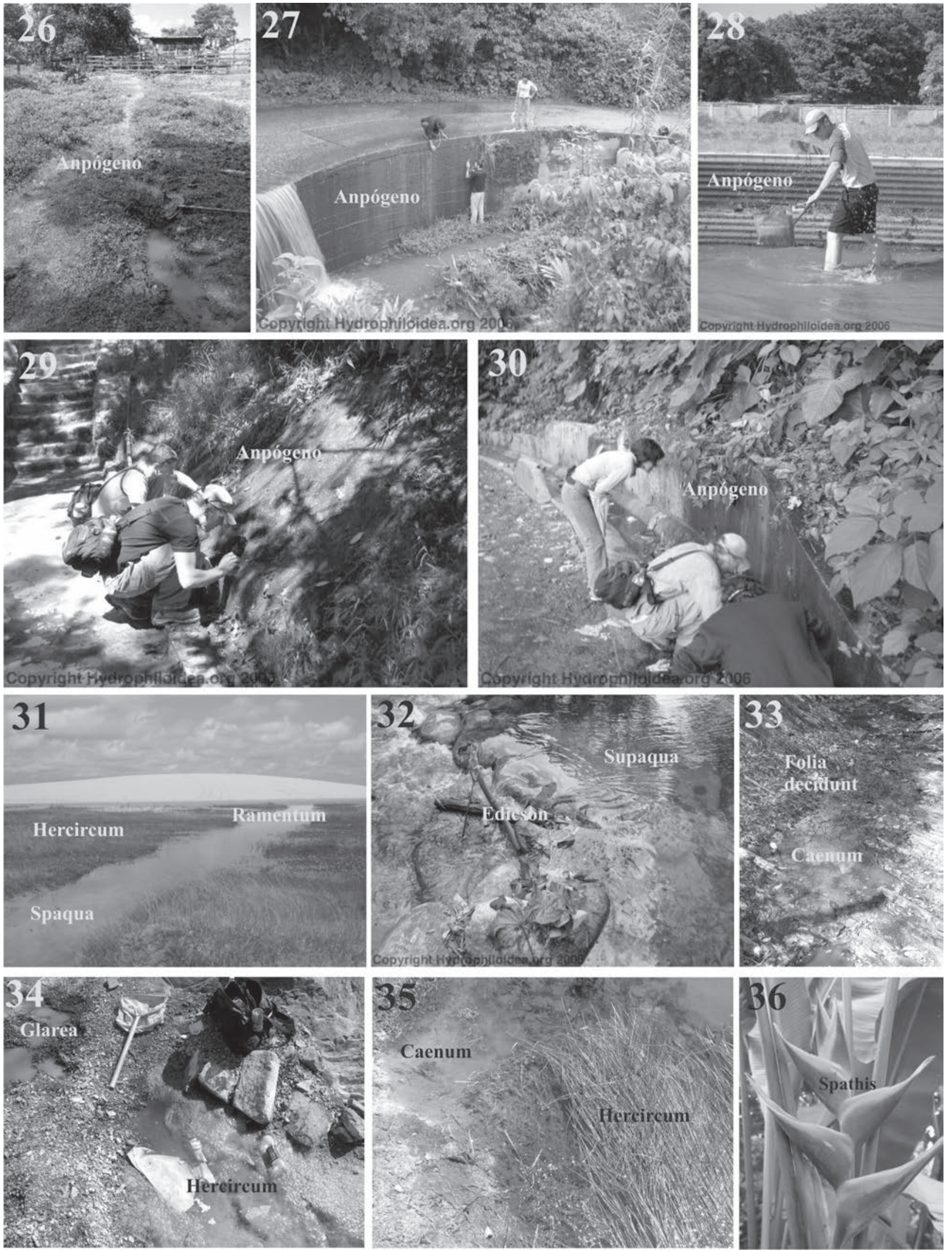